\title{
SALUD PÚBLICA Y ELECCIONES
}

\author{
Public health and elections
}

Los tiempos de la política no están necesariamente correlacionados con los tiempos de la salud pública. Mucho menos los tiempos electorales. Ese realismo no puede desconocer la posibilidad de un debate sobre salud pública, que involucrando a las candidaturas y las prioridades de temas tan urgentes como educación y democratización de la estructura constitucional, permita dialogar en forma ciudadana, desde nuestra especialidad.

Pese a que la reforma de salud como posibilidad de construir aquello que Dewey llamaba "públicos", en torno a los problemas de salud y enfermedad se acotó, en lo sustancial, a una parcial y belicosa política de medicamentos -con logros que valoramos- y a la Ley de deberes y derechos de pacientes, pensamos que el espacio del esfuerzo de dos décadas no está agotado. La importancia del sector público, del trabajo en red alrededor de prestaciones clínicas y el reconocimiento de la importancia de un trasfondo solidario en el funcionamiento del sector, son logros relevantes de los años posdictatoriales.

Las transformaciones ocurridas por la democratización, así como el desarrollo tecno-científico de estas décadas, relevan zonas desacompasadas en el campo de la salud. Los problemas que identificamos ojalá sean parte del debate electoral, pero relegados a una corta campaña no permitirán profundizar en su hondura y espesor. Los delineamos aquí como una invitación a nuestros lectores a hacerse parte de un debate público.

El financiamiento del sistema público sigue siendo una cuestión urgente. Nuevamente este año los hospitales aparecen con déficit antes de terminar el año. El debate sobre ineficiencia resulta monótono y hay una conciencia creciente de la necesidad de sincerar los reales costos de operación de los establecimientos. El gasto en salud seguirá creciendo y es hora de que el esfuerzo sea compartido. Hasta ahora el gasto de bolsillo ha sido predominante en áreas sensibles como medicamentos y áreas en falencia.

Quellón y Tocopilla en forma dramática han mostrado la existencia de notables desigualdades regionales en el acceso a prestaciones complejas y tecnologías. No podemos satisfacernos con planes centrales ni con urgentes intervenciones de la autoridad ministerial, es necesario trasladar capacidades decisoras, tanto técnicas como de gestión, a las regiones y a las redes 
locales. La inversión en equipos, especialistas y establecimientos, requiere estar situada en los territorios, disponiendo de una holgura presupuestaria para abordarla.

Chile requiere una política de medicamentos y tecnologías en salud. Esto implica dos cuestiones que enumeramos separadamente, pero que en este caso son críticas: investigación e información. Pensamos que UNASUR debe ser un marco apropiado para promocionar este debate, haciendo uso de las potencialidades y lecciones obtenidas por nuestros hermanos del cono sur. Necesitamos usar todas las potencialidades para un desarrollo nacional, incluyendo las claúsulas de la OMC y los TRIP.

Aunque algunos señalan que hemos perdido ya oportunidades en informatización del sistema, aún es posible concentrarse en uno que unifique los registros a nivel nacional y que permita brindar una atención con vista a la historia clínica de pacientes que cada día son más ubicuos. Producir este desarrollo implica un crecimiento notable en la experticia informática de todo el sistema y posibilita realizar la radical transformación en la producción de estadísticas de salud. Cambios que deben considerar no solo su despliegue en línea y en tiempos cada vez más oportunos, sino organizar las cifras de la economía de la salud, que siguen siendo un arcano. Ya sabemos que la producción de estadísticas nacionales se encuentra en una encrucijada difícil.

Y finalmente, sin un salto en la investigación en salud pública, nada de esto es posible. Una fuerte inyección de experimentalismo y pragmatismo, es imprescindible para producir resultados locales, pertinentes y útiles. Significa dejar en el trasto la epistemología popperiana tan al uso en nuestro sector y comprender algunas lecciones de los estudios de ciencia y tecnología (STS): constituimos nuestros objetos de estudio en el seno de nuestras investigaciones, no hay un preexistente que conocer ni una ontología previamente definida. Suena difícil, pero es sencillo: debemos destinar el $1 \%$ de nuestro gasto en salud a investigar. Al menos podemos considerar los puntos mencionados como una primera lista de áreas a estudiar. 